3-rd Workshop on Robot Motion and Control, 2002, Bukowy Dworek, Poland

\title{
DESIGN OF THE MECHATRONIC SYSTEM WITH HELP OF UML DIAGRAMS
}

\author{
Zbigniew Mrozek $\$$
}

\begin{abstract}
The Unified Modelling Language (UML) is a language that helps to visualize, design and document models of large and complex systems. Terminology and notation of visual modelling can be used as common high level object oriented language for design of the mechatronic systems.
\end{abstract}

Index terms UML, mechatronics, CASE tool, MATLAB, Simulink, Stateflow

\section{INTRODUCTION}

UML is widely used in designing complex and reliable informatics systems. It integrates the best practices of object oriented development and research $[1-3,6,8,16]$. It provides means for: capturing system requirements, modelling on high abstraction level, encapsulation and reuse of facilities. Control engineer will find it helpful to describe reactive behaviour of system states and to map software to physical architectures.

Using UML notation, an experienced developer may design systems with fewer defects in less time. The advantage of UML over other tools is that it reveals gaps and inconsistencies in the requirement's specification at very early stages of the design as well as providing the ease of modelling, understanding and modification of graphical diagrams of mechatronic systems [10].

\section{UML AS LANGUAGE AND DESIGN TOOL}

UML was originally developed in response to call for a proposal for a standardized object modelling language. Then it was improved many times until version UML 1.3 was accepted by the Object Management Group's (OMG) as proposal for standard in year 1999 .

UML was introduced as language for modeling of the information systems but can be used to describe all elements of mechatronic system. Many attempts were done to extend the UML applicability in the areas beyond informatics. McLaughlin [5] showed UML approach to process-control problem that contains a conveyor-belt transport subsystem. Using UML for real-time systems is presented in $[4,5,8,10]$.

\footnotetext{
\$ Cracow University of Technology, PL 31-155 Krakow, Poland, e-mail: zbigniew.mrozek@pk.edu.pl.
}

\section{USING UML DIAGRAMS IN MECHATRONIC DESIGN}

Any complex system can be presented by a set of carefully chosen models. Single model is not sufficient to describe real system. Use case diagram and class diagram (there are described later) are probably used in all UML supported projects. The choice of what other diagrams are created depend on how a problem is attacked.

Booch [1] says, the development process is set of partially ordered steps, which leads to desired target.

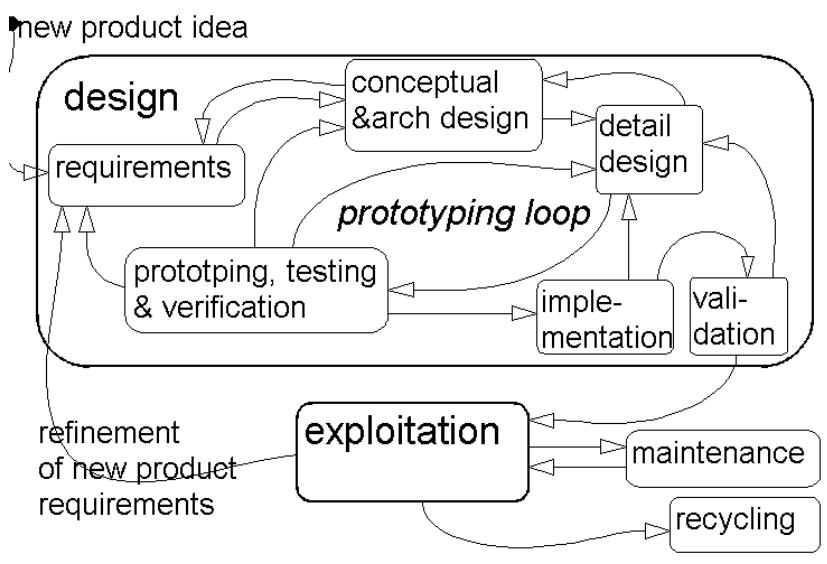

Figure 1 Designing is an iterative process, an important part of product life time.

Designing of mechatronic system is an iterative process, as designers often jumps back one or more steps to redesign or tune what they have done before. Redesigning UML diagrams on computer screen is supported with CASE software. Best known packages are Rational Rose [11] and RtS [12]. Using UML helps to find and to correct errors and omissions in requirements specification on very early phase of design, when models on high level of abstraction are prepared. Some CASE tools offer simulation and animation of UML models. This helps to verify if all requirements are fulfilled. Simulation is even more realistic if some extra tools (e.g. Altia ${ }^{\circledR}$ FacePlate ${ }^{\circledR}$ for RtS[12]) are used to build virtual but realistic operator console with animated dials and gauges.

Later CAD/CAM and CAE tools are used in detailed design of subsystems. Parameters from detailed design are used in simulation models. MATLAB, SIMULINK, STATEFLOW and other software is used to build virtual and HIL (hardware in the loop) simulation models. Simulation is 
used in prototyping to tune and verify behaviour of designed product before its physical model is prepared.

Scenario and names of most important UML diagrams are shown on figure 2. The diagrams are:

- use case diagram. It describes functional behaviour of the system as seen by the user (an actor),

- class diagram shows objects and classes, and relationships between them

- there are two interaction diagrams: sequence diagram (it shows object interactions arranged in time sequence) and collaboration diagram (it shows interactions organized around the structure of a model). Both describe dynamic behaviour of a system.

- state (statechart) diagram describes the dynamic behaviour in response to events and fulfilled conditions. Parallel activities may be shown on activity diagram.

- system architecture diagram should be used in mechatronic design. It is not included in current UML specification, but IT is supported by CASE too:, RtS from Artisan [12].

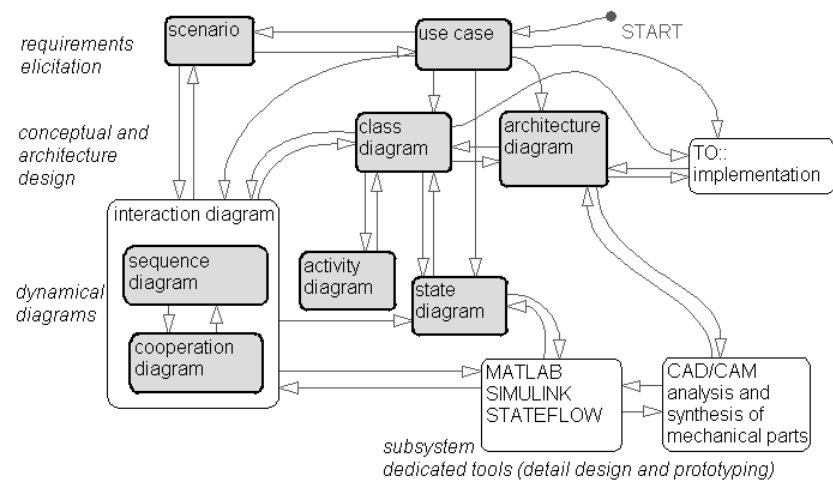

Figure 2 UML diagrams are supposed to be build in predefined order.

Figure 2 shows suggested order of building different UML diagrams.. Scenarios and preliminary version of use case diagram are prepared early with help of client or user of the future system. Than design team should analyse use cases and scenarios to identify objects, their responsibility, activities and parameters. This leads to preliminary version of class and object diagrams. Later objects and classes are used to build another diagrams. Class diagram is redesigned if new object, method or attribute is needed to build the other diagrams. Sequence of actions described in scenarios is graphically presented on sequence or collaboration diagram. All states (that an object may go through) are presented on state diagram.

\section{ACTOR, USE CASE DIAGRAM AND SCENARIO}

A starting point of design is requirements elicitation. The main tools used for requirements elicitation are use cases and scenarios. Use case diagram describes the functional behavior of the system as seen by an external user.

\section{A. Use case diagram}

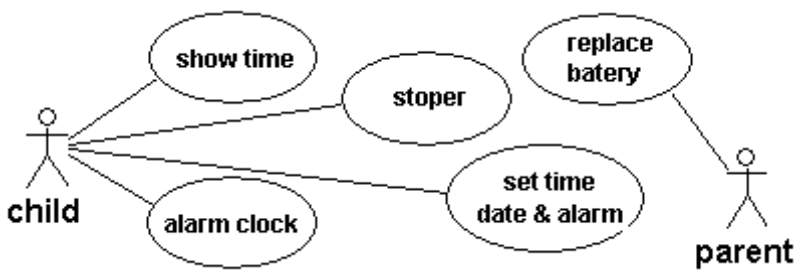

Figure 3 Use case diagram for electronic watch.

Figure 3 shows what a typical use case diagram looks like. A human user, another system, sensor or anything located outside of the actual system that will interact with the system is called an actor. When actor (e.g. "child") communicates with use case (a named oval on use case diagram, e.g "show time"), it means the actor sends messages or receive messages from the system. Actor is depicted as a simple icon of a man. Defining actors is essential to set the border between the system under development and its external environment.

Use case captures sub-system functionality as "black box" seen from the point of view of external user (e.g. "child"). Use case diagram is collection of use cases. It is on the highest level of abstraction of UML diagrams. It helps to understand how the system should work. It describes different behaviour of the system and shows how it interacts with external actors.

Preparing use case diagrams is an important job, as original problem description may be incomplete and some requirements may conflict with others. Both client and members of design staff should understand use cases. User should verify if all functionality of the future system is included in use case diagram and if all actors do communicate with respective use cases.

Any extra requirements which are not shown in use cases or scenarios may be included as constrains (restrictions or rules applied to various elements of a model). This is specially useful in real time systems, where timing constraints for latency of messages and processing time limits for operations should be followed. OCL (object constraint language [18]), pseudocode, annotations or text inside notes icon can be used to show constrains in UML models.

\section{B. Scenarios}

Scenarios are instances of use cases. A scenario is step-bystep descriptions of sequence of messages sent between actors and the system. Following scenario describes how an actor from figure 3 sets time: 
MODE button is pressed and watch display blinks with hour digits. Now user may increment hours (button 2 is pressed several times until display shows desired value of hours). When finished with hours, user may switch to minutes (he presses MODE button again and minutes are blinking). Now button_2 is used to increment minutes. If MODE is pressed again, digits of seconds will blink. Now it is not possible to increment seconds, as pressing button_2 will set zero value to seconds. If no button is pressed for 20 seconds, watch returns to its standard mode: show time.

There is large number of possible scenarios corresponding to a single use case. It is important to prepare few of non trivial scenarios including exception handling and error recovery.

\section{Tests}

Use cases and scenarios are useful to prepare tests for the system on early stage of the design. Otherwise team members may prefer to choose tests reflecting properties of actual system under design and client may expect to include properties, which extend agreed requirements specification.

\section{OTHER UML DIAGRAMS}

\section{A. Class and object diagram}

Class and object diagram shows internal structure of the system. It defines the system structure by identifying objects, defining their classes and relationships that exist between classes. Figure 7 shows an example of class diagram for robotized arc welding system [9].

Preliminary version of class diagram can be build quite easily. One can identify object as physical devices, sensors, actuators, interfaces etc. Use cases and scenarios should be analysed to find objects. Then if sequence, collaboration or any other diagram is build or changed, new classes may be defined and existing classes may affected. Other diagrams, which use affected classes may become invalid. CASE tools supporting UML programming will try to modify automatically all other diagrams to keep the system consistent. with. It will warn designer if automatic modification is not possible.

\section{B. Sequence and collaboration diagrams}

UML provides two notations for showing scenarios: sequence diagram and collaboration diagram. Figure 4 shows what a typical sequence diagram looks like.

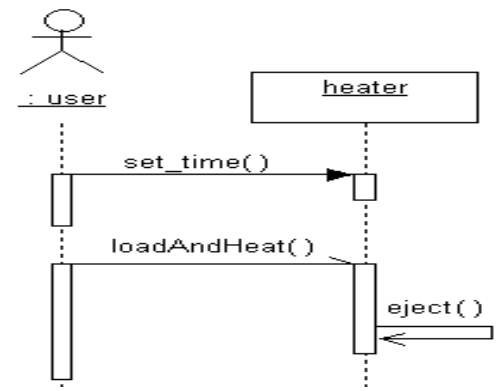

Figure 4 Sequence diagram for automatic toaster.

The sequence diagram present objects shown as icon on top of vertical time lines. Time flows down the line.. Object may send messages (shown as horizontal line with arrow) asking some services from another objects (e.g. user object asks heater object to set the heating time). Message may be send to self (e.g. to eject toast when ready). Activities shown on the sequence diagram may be annotated with text. Timing marks can be added to show exact time constrains.

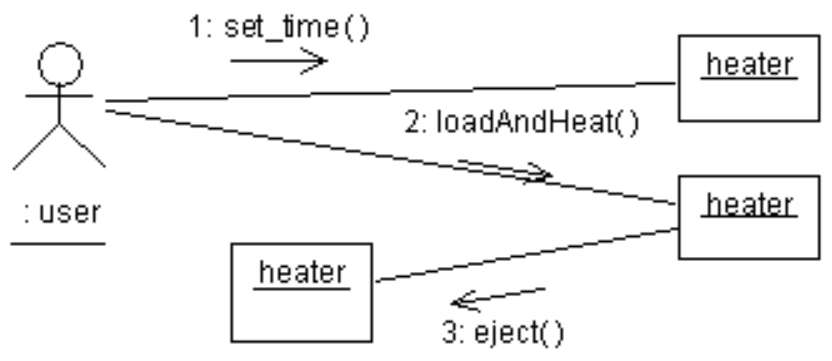

Figure 5 Collaboration diagram for automatic toaster.

Collaboration diagram (fig. 5) shows structural view of scenarios but provide essentially the same information as sequence diagram.

\section{State and activity diagram}

An important subset of all classes can be modelled using finite state machines. Such classes are called reactive because they react in specific ways to incoming events.

State diagram models behaviour of reactive entities by specifying its response to the receipt of events. It is used to describe behaviour of class instances, but state may also describe the behaviour of use case, actor, subsystem, etc [18]. Comparing with sequence diagram (it shows chosen scenario in time-based sequence), the state diagram shows all states the object may go through.

Each state represents a named condition during the life of an object. It stays in actual state as long as it satisfies some condition or until it is fired by some event to other state. 


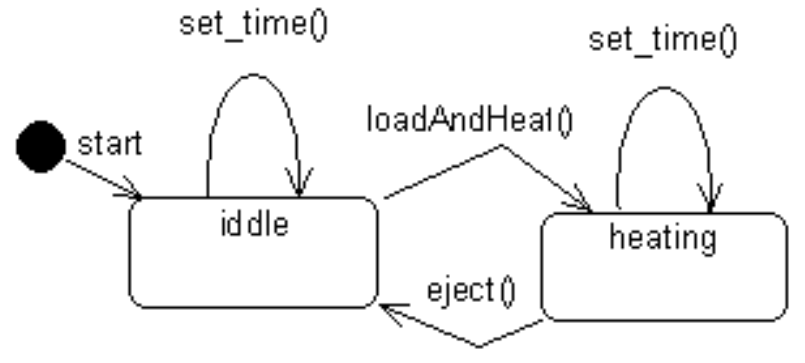

Figure 6 State diagram for automatic toaster.

A black ball shows a start state. An end state (if exists) is shown as black ball in a circle. Transitions (lines with arrow, fig. 6) connect the various states on the diagram. Decisions, synchronizations, and activities may appear on state diagrams (fig. 10).

Activity diagram (fig. 9) is used to visualise parallel activities and to show sequence of internal states.

\section{Implementation diagrams}

Original UML implementation diagrams (component and deployment diagrams) are dedicated to information systems and they are not very useful in mechatronic design. Using a system architecture diagram instead is strongly advised.

Once the system boundary of mechatronic system has been determined with use case diagram, physical interfaces to all actors should be identified as part of requirements for the system. Result can be presented on system architecture diagram. This is an extension of UML from RtS (Real time Studio) package [12]. Figure 7 shows all main subsystems of arc welding system. There are connected with CAN-bus communication network. This include operator console with I/O devices (keyboard, joystick, LCD display), work piece positioners, power source, robot controller and wire feeder. As the project is further investigated, more details is added. COTS (Commercial Off the Shelf) subsystems (mechanical, electrical, etc) are chosen and the requirements for any custom subsystems are defined. Later more details can be assigned to each element of this diagram. Double click on any item of UML diagram on computer screen opens properties window. One can assign network address and other parameters or information to chosen item using this window.

\section{MANAGEMENT OF INTERDISCIPLINARY DESIGN PROJECT}

The mechatronic design process can be split into few general phases:

- requirement specification,

- analysis, conceptual and architecture level design,

- detailed level design, prototyping and testing,

- implementation.

Requirements elicitation phase may decide on success or failure of the project. Inconsistency and incompleteness of requirements specification may affect prototyping or implementation phase of design if errors are not found on early stage of design, when project modification is relatively cheap.

Analysis phase includes decomposition and architecture level design of the future system. Large-scale strategic decisions about the system implementation affect all later steps of design. Number and responsibility of subsystems and how they are interconnected is decided.

A virtual model of the future system is designed during prototyping and testing phase. Some UML diagrams can be adopted for automatic generation of virtual model of the future mechatronic system. The virtual model is then prototyped in real time, in environment representing future working conditions of the final product [13-15].

During implementation phase, prototyping equipment should be replaced by a target system: cheaper, smaller, easier to operate and more reliable in industrial environment. $\mathrm{CAD} / \mathrm{CAM}$ and $\mathrm{CAE}$ tools are very useful during both: prototyping and implementation phase. For example digital electronic and computer electronic parts of the mechatronic system can be almost automatically designed in silicon as ASIC (application specific integrated circuit) hardware using FPGA (field programmable gate arrays) chips and software from Xilinx or Altera [15] .

\section{BRAINSTORMING}

Brainstorming is used to identify possible solutions to problems and potential opportunities for improvements. This technique is used for tapping creative thinking of a team to generate and clarify a list of ideas, problems and issues. Brainstorming can be used to find all use cases and and scenarios. Brainstorming is also useful to identify states and transitions for state diagram. There are two phases in the brainstorming procedure [8]:

- during the generation phase

- $\quad$ the purpose (target) of the brainstorming session is clearly stated

- each team member takes a turn in a sequence, stating a single idea

- if possible, new ideas are build on others ideas

- all ideas are recorded and should be seen by all the participants (using overhead is recommended)

- ideas are neither criticized nor discussed

- the process continues until no more ideas are generated.

- the clarification phase

- list of ideas should be reviewed to make sure that each person understands all the ideas

- evaluation of ideas will occur after the brainstorm session is completed. 


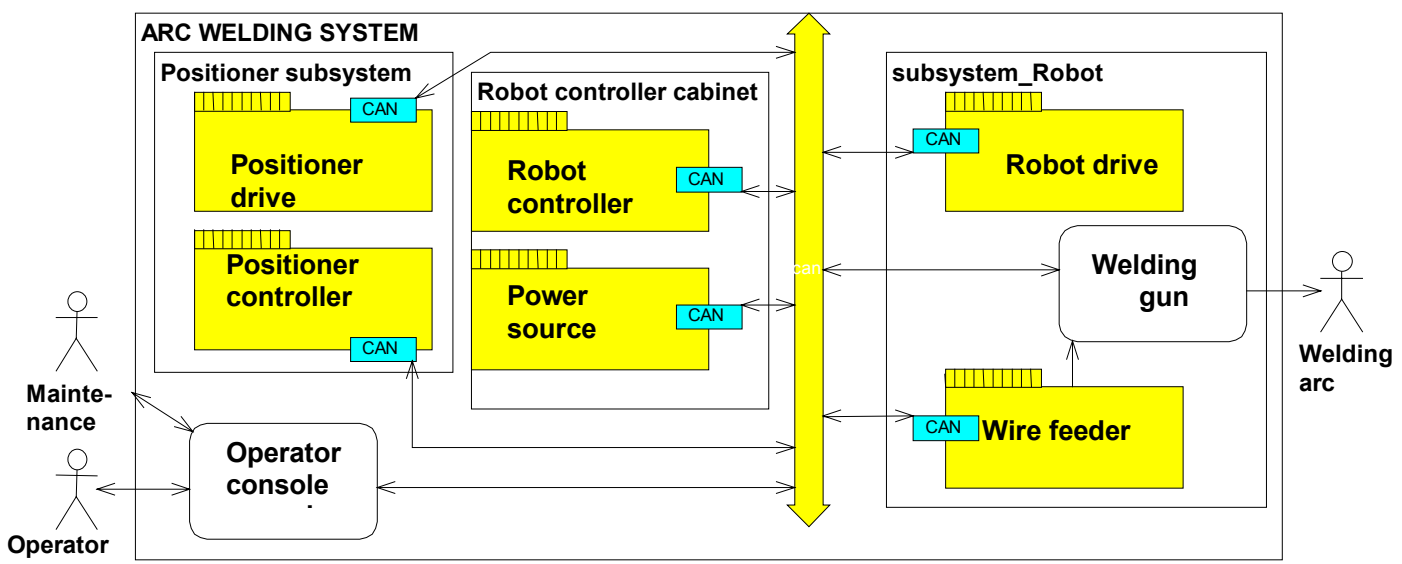

Figure 7 System architecture diagram for robotised arc welding system

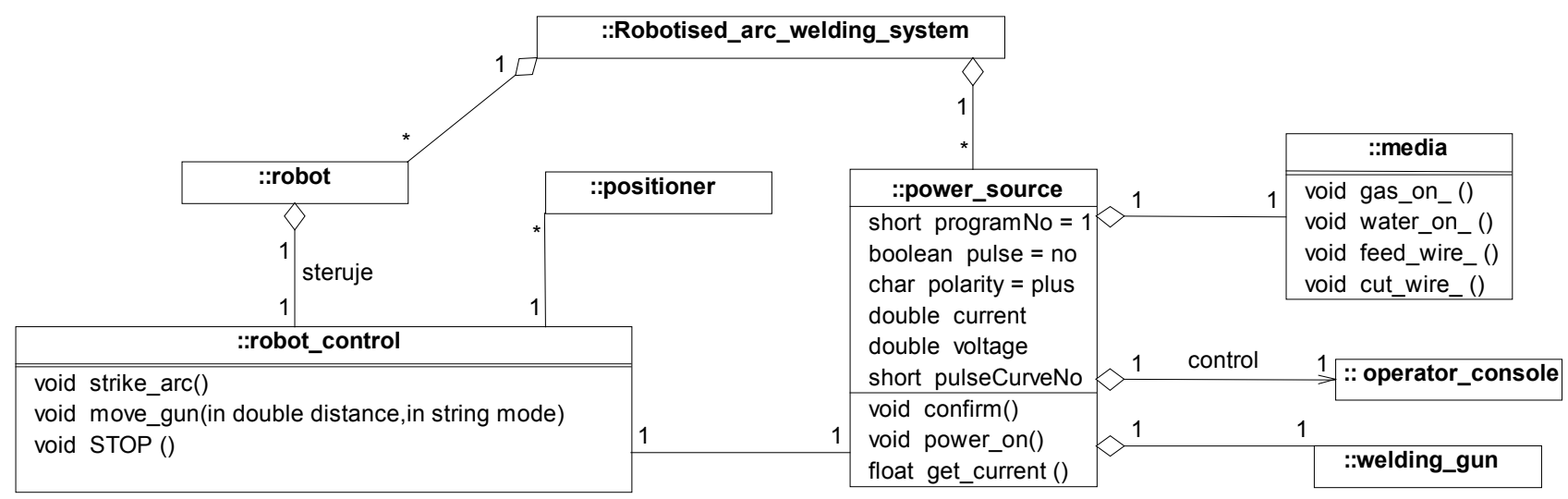

Figure 8 Class diagram for robotised arc welding system

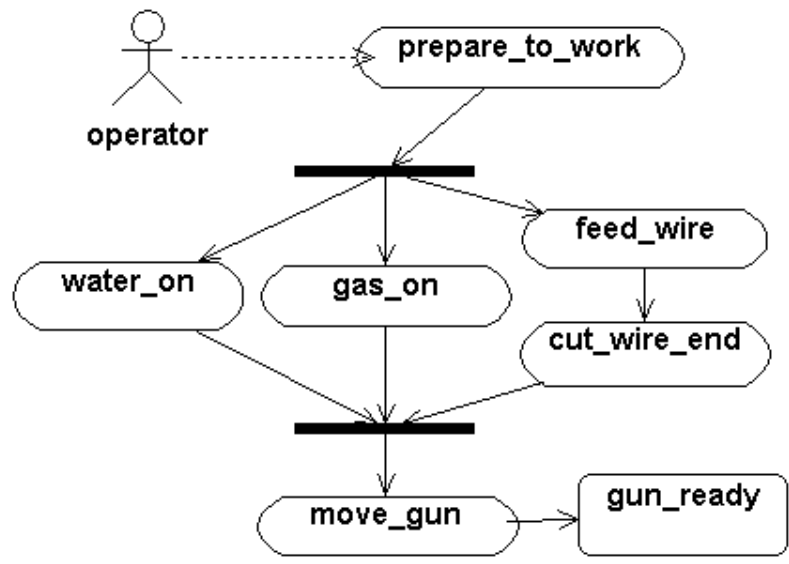

Figure 9 Activity diagram for robotized arc welding system 


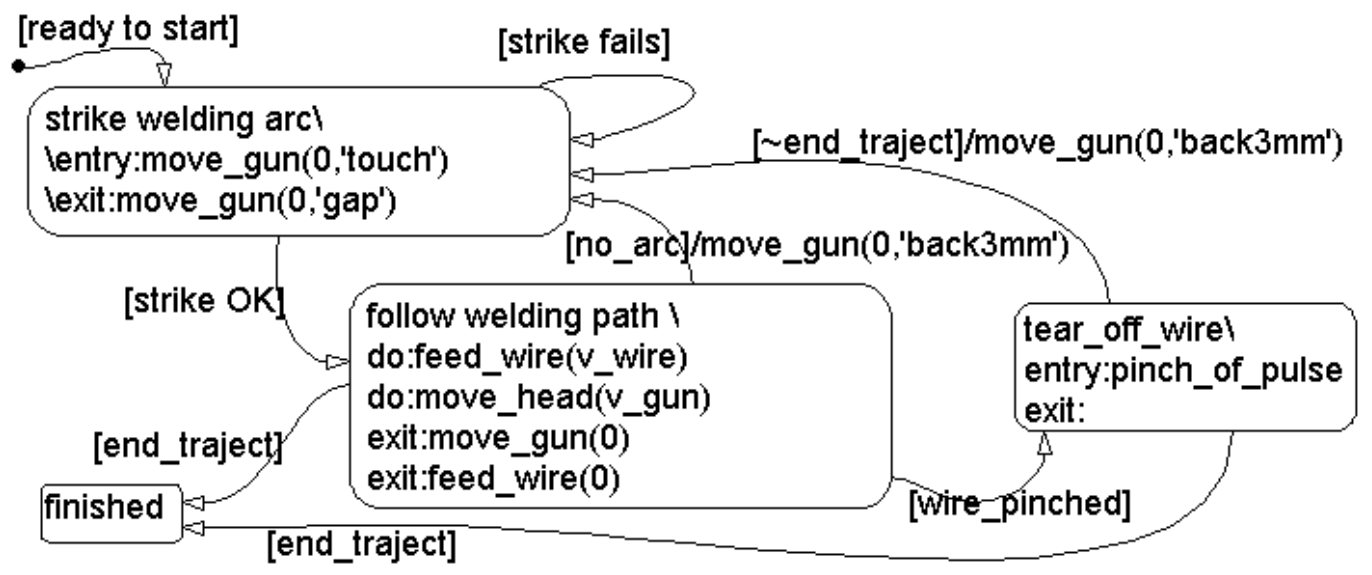

Figure 10 State diagram for robotized arc welding system

\section{CONCLUSIONS}

UML has facilities to help with requirements identification and extraction, capturing object structure and relationships and rigorous definition of behavior. It is supported by all major CASE tool vendors. UML reveals gaps and inconsistencies in the requirement's specification at earlier stages of software design, understand and modify visual modelling diagrams.

Unification and precision of notation is important for large and interdisciplinary projects. Designers may transfer already defined classes, communication networks, subsystems, and other elements between different diagrams and reuse them. This accelerates work progress and helps to keep all parts of project in a consistent manner.

Using commercially available specialised CAD/CAM and CAE tools and CASE packages, UML visual programming language may greatly improve productivity of a software design team by cutting down development time and improving final product quality (in accordance with ISO 9000 standards). UML is a dedicated software design language for large software projects, and its applicability can be extended to other domains, including mechatronics.

\section{ACKNOWLEDGEMENTS}

Author wants to express his gratitude to ARTiSAN Software Tools, Inc (GB); Rational Software Corporation (USA) and Premium Technology Sp zoo (Poland) for free evaluation licence for following software: Real-time Studio, Rational Rose Suite and Rational Rose RT. MATLAB and its libraries were given by The Mathwork Inc. and ONT (Poland),

\section{REFERENCES:}

[1] Booch, G. Rumbaugh, J. Jacobson I The Unified Modelling Language User Guide, Addison Wesley, 1999, WNT Warszawa 2000

[2] Bruegge B, Dutoit A, Object-Oriented Software Engineering: Conquering Complex and Changing Systems, Prentice-Hall, 1999,

[3] Douglas, B.P. Real-time UML: Developing Efficient Objects for Embedded Systems. Addison Wesley, 1998.

[4] Douglas, B.P. Designing Real-time Systems with UML, Part I-III, Embedded Systems, March, April, May 1998.

[5] McLaughlin Michael J., Moore Alan, Real-Time Extensions to $U M L$, Timing, concurrency, and hardware interfaces, Dr. Dobb's Journal December 1998

[6] Mrozek Z, UML as integration tool for design of the mechatronic system, in Second Workshop on Robot Motion and Control, pp 189194, ed. Kozlowski K, Galicki M, Tchoń K, Oct 18-20, 2001, Bukowy Dworek, Poland.

[7] Mrozek B,. Mrozek Z, MATLAB 6, poradnik użytkownika, ISBN 83-7101-449-X, PLJ Warszawa 2001.

[8] Mrozek Z, Mrozek B, Adjei O, Teaching object oriented software engineering with UML, 13-rd Annual Conf. on Innovations in Education for Electrical and Information Eng., York, 8-10 April 2002

[9] Mrozek Z, Metodyka wykorzystania UML w projektowaniu mechatronicznym, pp.25-28, Pomiary Automatyka Kontrola 1, 2002.

[10] Mrozek Z, Komputerowo wspomagane projektowanie systemów mechatronicznych, Zeszyty Naukowe PK, Kraków 2002,

[11] Rational Rose Suite,, Rational Rose RT and other software from Rational Software Corporation,

[12] Real-time Studio, ARTiSAN Software Tools, Inc. July 2001,

[13] Uhl T (editor), Wybrane problemy projektowania mechatronicznego, Katedra Robotyki i Dynamiki Maszyn, AGH 1999.

[14] Uhl T, Bojko T, Mrozek Z, Szwabowski W, Rapid prototyping of mechatronic systems, Journal of Theoretical and Applied Mechanics, pp.655-668, vol.38.3, 2000

[15] Uhl T, Mrozek Z, Petko M Rapid control prototyping for flexible arm, Preprints of 1-st IFAC Conference on Mechatronic Systems, vol II, pp 489-494, Darmstadt, September 18-20, 2000.

[16] Uhl T System komputerowego wspomagania projektowania mechatronicznego, Pomiary Automatyka Kontrola Nr 1, pp.14-17, 2002

[17] UML for Real Time System Design,, ISG 1998

[18] OMG Unified Modeling Language Specification, ver. 1.4, Sept. 2001. (and other OMG: Object Management Group documents) http://www.omg.org 